\title{
The relevance of the psychometrist category as a professional resource: Training-related issues
}

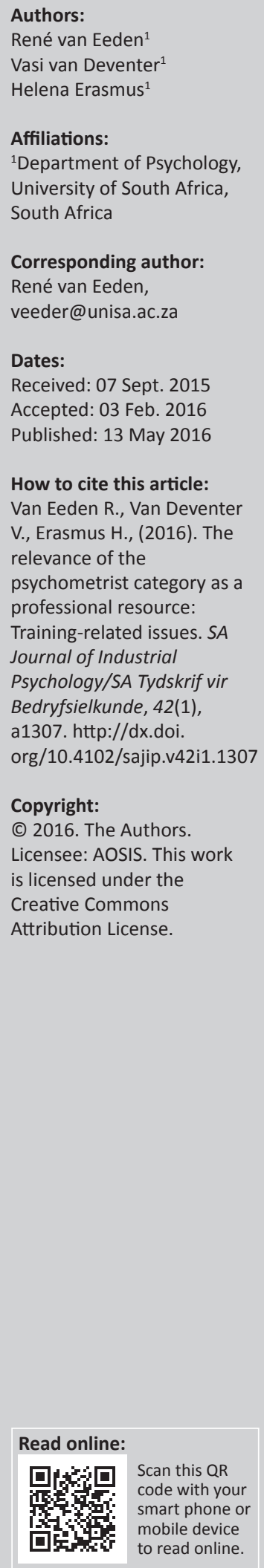

Authors:

René van Eeden

Affiliations:

Department of Psychology,

University of South Africa,

th Afric

René van Eeden,

Dates:

Received: 07 Sept. 2015

Accepted: 03 Feb. 2016

How to cite this article:

Van Eeden R., Van Deventer

V., Erasmus $H_{1}$, (2016). The

psychometrist category as a

professional resource:

Journal of

g/10.4102/sajip.v42i1.1307

Copyright:

Licensee: AOSIS. This work

is licensed under the

Creative Commons

Attribution License.

\begin{abstract}
Orientation: The professional status of psychometrists places them in a position where they can provide a specialist function independently and their services should therefore be relevant to a variety of settings.
\end{abstract}

Research purpose: The aim was to explore if the training of student psychometrists contributes to the relevance of this category in terms of the demographic profile of student psychometrists, the scope of services potentially provided by them and the content of training programmes.

Motivation for the study: There is a paucity of research on training in the psychometrist category.

Research design, approach and method: Data were obtained from the files of a cohort of student psychometrists who were registered in the Department of Psychology at the University of South Africa (UNISA). Follow-up surveys on training and work contexts were conducted amongst these students and their in-practice supervisors to confirm and supplement the data. In addition, a survey on the national availability of training programmes for psychometrists was conducted at South African universities.

Main findings: Gender and racial skewness in terms of the demographic profile of the UNISA students seemed to reflect a national trend. In terms of the scope of services, training opportunities and perceived job opportunities for psychometrists seemed limited and despite the utilisation of the skills area in all the applied contexts, concerns related to the sectors being served were identified. With regard to the content of the training programmes, students and in-practice supervisors expressed a need for greater preparation in test use before related practical experience takes place. The importance of the university's involvement during the practicum was also emphasised.

Practical/managerial implications: Recommendations are made regarding the structure and content of training programmes. This information could be applied in adapting existing programmes and in developing new programmes.

Contribution/value-add: Ultimately, these recommendations could contribute to the value of the psychometrist category as a professional resource relevant to a variety of settings.

\section{Introduction}

Psychology was first recognised as a profession in South Africa in 1974. Since then, there have been various changes in the levels of professional registration and the categories defined in each level (Abel \& Louw, 2009; Pretorius, 2012). The skills area of psychometrist, however, has been consistently defined as a specialist registration category. Professional practice currently includes registration as a psychologist (with five subcategories) and, at a second tier, registration as a registered counsellor or psychometrist (Pretorius, 2012). The 2014 register of the Health Professions Council of South Africa (HPCSA) comprises 8172 psychometrists (HPCSA, 2014a). Internationally, the psychometrist's functions seem to be included in psychologists' scope of practice and not singled out as an independent practice. However, this may change given the establishment of a National Association of Psychometrists (NAP) in the United States and the fact that testing provided by these 'supervised technicians' received a professional billing code in 2006 (NAP, 2014).

As an established sub-discipline of psychology, psychometrics is included in the teaching of the subject at pre-graduate and post-graduate levels. The potential role of psychometrists in the test development process is gaining importance (Labourwise, 2014; Pretorius, 2012), and the principles of psychometric theory should therefore be emphasised in their teaching and training. Of equal importance is an awareness of the history of test development in South Africa and the 
related controversies (Foxcroft, Roodt \& Abrahams, 2013; Laher \& Cockcroft, 2013). When preparing students for professional registration, the focus shifts to the principles and practices underlying psychological assessment and the use of assessment measures. This skills area is incorporated in training for all the professional registration categories in psychology. However, elevating it to a professional level places psychometrists in a position where they can provide a specialist function independently. It also gives psychologists an option of sourcing related work to psychometrists in independent practice. Pretorius (2012, p. 515) states that this category is undervalued and that psychometrists may be regarded as 'lackeys of psychologists' (Pretorius, 2012, p. 515). We propose that their position in the professional model should be defined in terms of their function as independent practitioners providing a professional resource.

The present study considered the extent to which the psychometrist category could be regarded as a professional resource relevant to a variety of settings. More specifically, the contribution of the training of student psychometrists to the relevance of this category was explored. Based on a literature review, relevance was defined in terms of the demographic profile of student psychometrists, the scope of services potentially provided by them and the content of the training programme.

\section{Research purpose and objectives}

Previous research in psychometrics has primarily focused on test development and validity studies (e.g. Hill et al. 2013; Metzer, De Bruin \& Adams, 2014; Schaap, 2011; Van Zyl \& Taylor, 2012; Visser \& Viviers, 2010). Minimal attention has been paid to the teaching and training of psychometrists. An exception is a study on assessment centre-related training (Mulder, Jorgensen, Nel \& Meiring, 2013). Issues surfacing from the much published debate on the feasibility of the registered counsellor category are yet to be explored in relation to the psychometrist category. The category of registered counsellor was established to make primary psychological services available at a community level, especially to the previously disadvantaged. Research showed that this category does not appear to sufficiently fulfil this aim. The implications of these findings and potential solutions were discussed by authors such as Abel and Louw (2009) and Elkonin and Sandison (2006, 2010). A need for relevant psychological services is echoed in the research on clinical psychology training in South Africa. Pillay, Ahmed and Bawa (2013) recommended structural and curriculum-related changes to align the services rendered with the mental health needs of communities and individuals.

There is a lack of related research on the training of psychometrists. The aim of the present study was to explore if the training of student psychometrists contributes to the relevance of this category in terms of the demographic profile of student psychometrists, the scope of services potentially provided by them and the content of training programmes. The focus was on a cohort of students at a specific university and these findings were contextualised in terms of the national availability of training for psychometrists. Surveys were conducted with three participant groups (i.e. student psychometrists, in-practice supervisors and university departments) and the results are reported below for each of these groups. This information is subsequently integrated in the discussion on the three issues related to relevance. The manuscript concludes with recommendations regarding the structure and content of training, which could contribute to the value of the psychometrist category as a professional resource relevant to a variety of settings.

\section{Literature review}

The contribution of the training of professionals in psychology to the relevance of psychological services is discussed in the literature. The issues raised can be grouped into three categories related to student demographics, the scope of services and the content of training programmes. Although the available research focused primarily on the categories of registered counsellor and psychologist, the findings reflect the local sociopolitical context and are therefore relevant regardless of registration category.

Firstly, representation in terms of the demographic profile of students and professionals in these fields was examined. In terms of gender, race $^{1}$ and geographical distribution, research has found that students and professionals in the registered counsellor category were predominantly female, white and worked in urban areas (Abel \& Louw, 2009; Du Preez \& Roos, 2008; Elkonin \& Sandison, 2006). The gender distribution was consistent with national and international trends in psychology (Pillay \& Johnston, 2011). Racial skewness, in professional training in general, was problematic in that the majority of the students were white despite efforts to change the profile of the student population (e.g. Pillay et al. 2013; Pillay \& Siyothula, 2008). This raises concerns if one considers the language difficulties reported by trainees and practitioners (Pillay \& Harvey, 2006; Pillay \& Johnston, 2011). '(M)ost of the nation are either not receiving psychological care at all, or are receiving care in a language in which they are not comfortable or proficient' (Pillay \& Siyothula, 2008, p. 726). However, in the case of psychological assessment, one should keep in mind that there are potential disadvantages to home language testing (Nell, 1999). South African children and adults are often educated in English, and certain terms and concepts are acquired through the medium of English (Foxcroft, 2011). English is also the most common language of communication between population groups in South Africa (Schoeman, De Beer \& Visser, 2008). In both research and practice, the role of language in test use and interpretation continues to receive attention (Laher \& Cockcroft, 2013).

Secondly, the scope of psychological services was deemed inadequate. The main issues are the availability of professionals across different levels of registration and the availability of

1.The role of race in the relevance debate is by no means static. However, in the South African context it remains a factor in the categorisation of people in terms of African context it remains a factor in the categorisation of people in terms of
opportunities and resources. As such, the related classifications were used in the present study. 
services across geographical areas and sectors. Pillay et al. (2013) and Pillay and Kritzinger (2007), discussed obstacles in the national efforts to provide equitable services. Amongst others, problems relating to the availability of service providers at various levels and of services in rural and periurban areas were identified. The professional model partly determines sufficiency in terms of the registration of professionals at all levels. Practical issues, however, also play a role as seen in the case of registered counsellors. Despite the perceived value of registered counsellors across a variety of settings, research showed that the percentage of graduates who registered in this category was low (Abel \& Louw, 2009; Elkonin \& Sandison, 2006, 2010; Kotze \& Carolissen, 2005). In some instances less than a quarter of the students registered. Furthermore, less than half of those registered actually worked as counsellors. Problems during the registration process and a lack of employment opportunities were identified in these studies as some of the reasons for these trends. Research findings showed skewness in the availability of services across geographical areas with mixed findings in terms of the sectors served. Abel and Louw (2009) reported a relatively balanced distribution of services between the public sector and NGOs on the one hand and private practice and the private sector on the other. Elkonin and Sandison (2006) and Pretorius (2012), however, regarded private practice as oversaturated in relation to the needs of communities. Recommendations in this regard should, however, take note of the nature of the service rendered. For example, the fact that the private sector is the largest employer of industrial psychologists is to be expected (Benjamin \& Louw-Potgieter, 2008).

In the third place, the content of teaching and training programmes was critically evaluated in terms of their relevance to the South African context. There is a call for greater emphasis on primary healthcare and on the relationship between culture and mental health that has implications for the training of professionals in the discipline (Pillay et al. 2013). The relevance of these health-related concerns for all registration categories has been questioned (Abel \& Louw, 2009), but the contexts in which psychometrists work, justify the continued research on multicultural assessment and related teaching. There is an ongoing debate on the feasibility of testing per se in South Africa (Foxcroft et al. 2013), but this was not the focus of the present study. The researchers proceeded from the assumption that testing forms an established part of psychological assessment but that the teaching and training in this sub-discipline should create an awareness of the controversies that apply in the local context. The three issues identified were explored for student psychometrists thus partly addressing the lack of related literature for this category.

\section{Research design \\ Research approach}

An exploratory approach was utilised to analyse secondary data (i.e. existing student data) as well as survey data. Descriptive statistics are reported and open-ended responses thematically categorised.

\section{Research method}

The focus was on a cohort of students at a specific university. Secondary data were obtained from the files of the student psychometrists who were registered for the equivalence programme in the Department of Psychology at UNISA from 2006-2011. Questionnaires were also distributed to the UNISA students $^{2}$ and their in-practice supervisors in 2014 to confirm and supplement the older data. To contextualise these findings, the present authors conducted a survey in 2014 on the availability of training programmes for psychometrists at all South African universities (Van Eeden, Van Deventer \& Erasmus, 2015).

\section{Research participants}

There were three participant groups.

Data from the files of the 154 student psychometrists, who were registered for the UNISA programme from 2006-2011, were analysed. This can be considered a non-probability, purposive sample. To confirm and supplement the information obtained from the files, a follow-up questionnaire on their training and work contexts was sent electronically to those students for whom contact details were available $(n=146)$ and 36 students (25\%) responded. According to Jordaan, Spangenberg, Watson and Fouché (2007), when the research is conducted via the Internet (as in the present study), a response rate in the lower twenties could still provide useful data. Nevertheless, the potential impact on the generalisability of the results should be kept in mind. Biographical details for the student sample are provided in Table 1 . The sample consisted of primarily female students situated in Gauteng, the Western Cape and KwaZuluNatal. More than half of these students were white.

An electronic questionnaire on training and work contexts was also sent to the 119 in-practice supervisors who were

TABLE 1: Biographical composition of the UNISA student psychometrists in terms of gender, race and geographical area.

\begin{tabular}{|c|c|c|c|c|}
\hline \multirow[t]{2}{*}{ Variable } & \multicolumn{2}{|c|}{ Total sample $(n=154)$} & \multicolumn{2}{|c|}{ Survey sample $(n=36)$} \\
\hline & Number & $\%$ & Number & $\%$ \\
\hline \multicolumn{5}{|l|}{ Gender } \\
\hline Female & 138 & 89.6 & 32 & 88.9 \\
\hline Male & 16 & 10.4 & 4 & 11.1 \\
\hline \multicolumn{5}{|l|}{ Race } \\
\hline White & 101 & 65.6 & 25 & 69.4 \\
\hline African & 22 & 14.3 & 4 & 11.1 \\
\hline Asian & 15 & 9.7 & 7 & 19.4 \\
\hline Mixed-race & 5 & 3.2 & - & - \\
\hline Unknown & 11 & 7.2 & - & - \\
\hline \multicolumn{5}{|l|}{ Province } \\
\hline Gauteng & 88 & 57.1 & 11 & 50.0 \\
\hline Western Cape & 33 & 21.4 & 3 & 13.6 \\
\hline KwaZulu-Natal & 19 & 12.3 & 6 & 27.3 \\
\hline Limpopo & 6 & 3.9 & - & - \\
\hline Eastern Cape & 3 & 1.9 & - & - \\
\hline North West & 2 & 1.3 & 1 & 4.5 \\
\hline Mpumalanga & 2 & 1.3 & 1 & 4.5 \\
\hline Northern Cape & 1 & 0.6 & - & - \\
\hline
\end{tabular}

2.To ensure consistency, the term "students' is used for the sample in the follow-up survey although these individuals were no longer enrolled in the programme. 
involved in the UNISA programme. Responses were received from 26 supervisors (22\%). Dated contact details were partially responsible for the low response rate.

The findings for the UNISA students were contextualised in terms of the national availability of training for psychometrists. The Psychology, Industrial Psychology and Educational Psychology Departments at 18 South African universities were invited to participate in an electronic survey on training programmes for second-tier registration. A total of 48 departments were contacted. Feedback regarding the availability of programmes was received from 34 departments, that is, a response rate of $63 \%$. Combined with HPCSA (2013) records, this information enabled the researchers to evaluate the national availability of training for psychometrists. In addition, details regarding the content of the programmes were obtained from 7 of the 34 departments enabling tentative conclusions on training models in general.

\section{Measuring instruments}

The measuring instruments consisted of:

An electronic questionnaire that was sent to the student psychometrists who were registered for the UNISA programme. This questionnaire comprised 20 items requesting biographical information, and details on their registration status and work contexts. They were also asked to comment on whether their theoretical training and the practical experience had prepared them for their current employment. An open-ended question allowed them to reflect on the degree content, the registration process and opportunities for psychometrists in general.

An electronic questionnaire that was sent to the in-practice supervisors who were involved in the UNISA programme. The questionnaire comprised 10 items on the current work contexts of the supervisors including reference to the assessments done. They also had to indicate the opportunities available at their place of employment for student psychometrists and psychometrists. Again an opportunity was provided for reflection on the degree content, the registration process and opportunities for psychometrists in general.

An electronic questionnaire that was sent to the universities. This questionnaire comprised 22 items that explored the availability, as well as the structure and content of training programmes, for second-tier registration.

\section{Research procedure and ethical considerations}

Data for the student psychometrists were obtained from the application forms, the in-practice supervisors' reports, the student portfolios and the HPCSA Form 225. The HPCSA register of psychometrists was consulted to determine how many of the students were registered (HPCSA, 2014a). The two electronic questionnaires on training and work contexts were sent to all the students who were enrolled in the UNISA programme and their in-practice supervisors. Initially, the electronic questionnaire on the availability of training programmes was sent to the university departments. This was followed by e-mail and telephonic requests for the relevant information.

Ethical clearance for the research project was granted by UNISA. University web pages and the HPCSA's (2013) list of accredited programmes, which are public, were used to confirm information in mapping the availability of programmes. Access to the HPCSA's (2014a) register of psychometrists also does not violate privacy laws as this is a public document. Consent was given by all the departments who provided detail on the structure and content of their programmes (i.e. those that completed the survey) and also by all the students and supervisors who completed the surveys. In addition, the results are reported in a manner that ensures anonymity and confidentiality.

\section{Analysis}

Frequency distributions for quantifiable variables are reported together with additional information obtained by means of cross-tabulations. The responses to the open-ended questions in the follow-up surveys were thematically categorised.

\section{Results}

The results are reported separately for the three participant groups. These are then integrated in a discussion that addresses the three issues identified in the literature review.

\section{Student psychometrists}

The student psychometrists, who were enrolled for the UNISA programme, had completed their honours degrees at different universities countrywide before entering the equivalence programme at UNISA. The majority (58\%) were UNISA graduates. Ninety-six $(62.3 \%)$ of the students were included in the 2014 HPCSA register of psychometrists (HPCSA, 2014a). ${ }^{3}$ Details on their placement contexts are provided in Table 2 . The majority of the students preferred a full-time placement with most of them completing the practical training at a single placement. Representation in the various categories (clinical, counselling, educational and industrial) corresponded with the prevalence of certain client groups. The placement supervisors were primarily registered as psychologists with a number of them registered in more than one category. The placement programmes and reports on the student files indicated that a total of more than 300 tests formed part of the training of the student psychometrists. To identify those tests, used most often during the placement training, an arbitrary cut-off of $25 \%$ was used. That is, a test had to be included as part of the training of more than a quarter of the students to be regarded as frequently used. These tests are listed in Table 3. In line with the HPCSA requirements, the student psychometrists gained experience in a broad range of tests 3.The personal detail available on the student files was used to search the register and the search was therefore not necessarily exhaustive. 
TABLE 2: Practical training and placement contexts of the Unisa student psychometrists.

\begin{tabular}{|c|c|c|}
\hline Duration $(n=154)$ & Number & $\%$ \\
\hline Full time & 128 & 83.1 \\
\hline Part time & 23 & 14.9 \\
\hline Unknown & 3 & 1.9 \\
\hline \multicolumn{3}{|l|}{ Number of placements $(n=154)$} \\
\hline One placement & 134 & 87.0 \\
\hline Two placements & 19 & 12.3 \\
\hline Three placements & 1 & 0.6 \\
\hline \multicolumn{3}{|c|}{ Completion of practical training $(n=154)$} \\
\hline Completed & 132 & 85.7 \\
\hline Cancelled & 22 & 14.3 \\
\hline \multicolumn{3}{|l|}{ Contexts $(n=174)$} \\
\hline Clinical & 12 & 6.9 \\
\hline Counselling & 62 & 35.6 \\
\hline Educational & 32 & 18.4 \\
\hline Industrial & 68 & 39.1 \\
\hline \multicolumn{3}{|l|}{ Client group $(n=169)$} \\
\hline Children and adolescents only & 30 & 17.8 \\
\hline Children and adolescents and adults & 55 & 32.5 \\
\hline Adolescents and adults only & 21 & 12.4 \\
\hline Adults only & 63 & 37.3 \\
\hline \multicolumn{3}{|c|}{ Registration category of the placement supervisor $(n=169)$} \\
\hline Clinical & 40 & 23.7 \\
\hline Counselling & 38 & 22.5 \\
\hline Educational & 33 & 19.5 \\
\hline Industrial & 30 & 17.8 \\
\hline Research & 1 & 0.6 \\
\hline Psychometrist & 5 & 3.0 \\
\hline More than one category & 16 & 9.5 \\
\hline Unknown & 6 & 3.6 \\
\hline
\end{tabular}

TABLE 3: Tests generally included in the practical training according to category.

\begin{tabular}{|c|c|}
\hline Variable & Test \\
\hline \multirow[t]{3}{*}{ Individual intelligence tests } & Junior South African Individual Scales (JSAIS) \\
\hline & Senior South African Individual Scale-Revised (SSAIS-R) \\
\hline & Wechsler Adult Intelligence Scale (WAIS) \\
\hline Group tests of intelligence & Raven's Progressive Matrices (APM, RPM, CPM, SPM) \\
\hline Learning potential tests & Cognitive Process Profile (CPP) \\
\hline \multirow[t]{3}{*}{ Aptitude tests } & Aptitude Test for School Beginners (ASB) \\
\hline & Differential Aptitude Tests (DAT) \\
\hline & Senior Aptitude Test (SAT) \\
\hline \multirow[t]{3}{*}{ Specific cognitive functions } & Bender Visual-Motor Gestalt Test (Bender-Gestalt) \\
\hline & General tests of mathematic proficiency \\
\hline & General tests of reading and spelling \\
\hline \multirow[t]{7}{*}{ Personality questionnaires } & High School Personality Questionnaire (HSPQ) \\
\hline & Fifteen Factor Questionnaire + $(15 \mathrm{FQ}+)$ \\
\hline & Sixteen Personality Factor Questionnaire (16PF) \\
\hline & Jung Personality Questionnaire/Type Indicator (JPQ/JTI) \\
\hline & Myers-Briggs Type Indicator (MBTI) \\
\hline & Occupational Personality Profile (OPP) \\
\hline & Occupational Personality Questionnaire (OPQ) \\
\hline Projective tests & Goodenough-Harris Draw-a-Person test (DAP) \\
\hline \multirow[t]{3}{*}{ Interest questionnaires } & 19 Field Interest Inventory (19FII) \\
\hline & South African Vocational Interest Inventory (SAVII) \\
\hline & Self-directed Search Questionnaire (SDS) \\
\hline $\begin{array}{l}\text { Learning styles and } \\
\text { value scales }\end{array}$ & Value Scale (VS) \\
\hline
\end{tabular}

catering to different age groups. It is interesting to note that only approximately a quarter of the psychometrists who responded to the follow-up survey used computer-based and Internet-delivered assessment.
In their replies to the follow-up survey, $47.2 \%$ of the respondents indicated that their theoretical training adequately prepared them for the practical placement and $75 \%$ indicated that their supervision adequately contributed to the required skills. The reasons for not registering as a psychometrist included a lapse in the required time period, problems with the registration process and pursuing an alternative registration category. Of those respondents who registered as psychometrists and who were employed in a context involving assessment $(n=22), 81.8 \%$ indicated that their training at the placement was relevant to their job. The rest of the sample indicated that they were partly prepared with only a few indicating that they were unprepared.

In terms of the theoretical training, limitations in the teaching of core skills were mentioned. The areas identified included instrumental knowledge and skills, communication and interpersonal skills, and practice management and referral skills:

The theoretical training did not cover sufficient statistical concepts to fully understand psychometric test development and results interpretation.

Administration and use of assessments would have complemented the theoretical training.

In terms of the practical placements, inadequate supervision, a lack of experience in contingency management and insufficient contextual knowledge were mentioned:

I needed to do additional certification ... which is costly. I furthermore required additional exposure in the corporate environment seeing as this was not covered adequately during my internship.

I was completely unprepared as to what to expect in a variety of sessions as well as how to handle clients who fall outside the "norm" ...

General comments on the degree programme, registration and opportunities for student psychometrists and psychometrists are presented in Box 1 and integrated in the discussion section.

\section{In-practice supervisors}

Supervisors indicated that a range of tests was used in the contexts where they worked and approximately half of them used computer-based and Internet-delivered assessment. The majority of the supervisors $(80.8 \%)$ indicated that their context had placement opportunities for student psychometrists, whereas only about half $(53.8 \%)$ had employment opportunities for psychometrists. General comments on the degree programme, registration and opportunities for student psychometrists and psychometrists are presented in Box 2 and integrated in the discussion section.

\section{University survey}

Eighteen South African universities were requested to partake in the study. This amounted to a total of 48 departments. Thirty-four of these departments responded with six departments presenting a programme that leads to registration 
BOX 1: Survey student sample: Examples of general comments on the degree programme, registration and opportunities for student psychometrists and psychometrists.

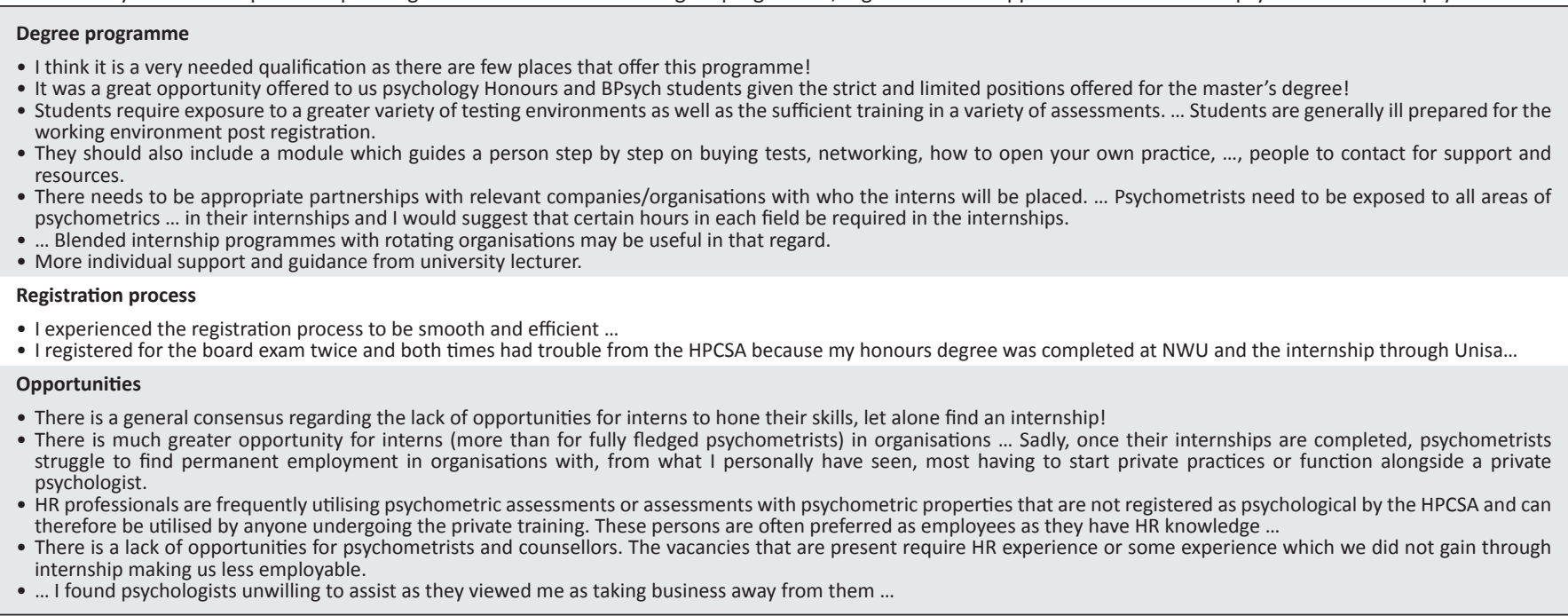

BOX 2: In-practice supervisor sample: Examples of general comments on the degree programme, registration and opportunities for student psychometrists and psychometrists.

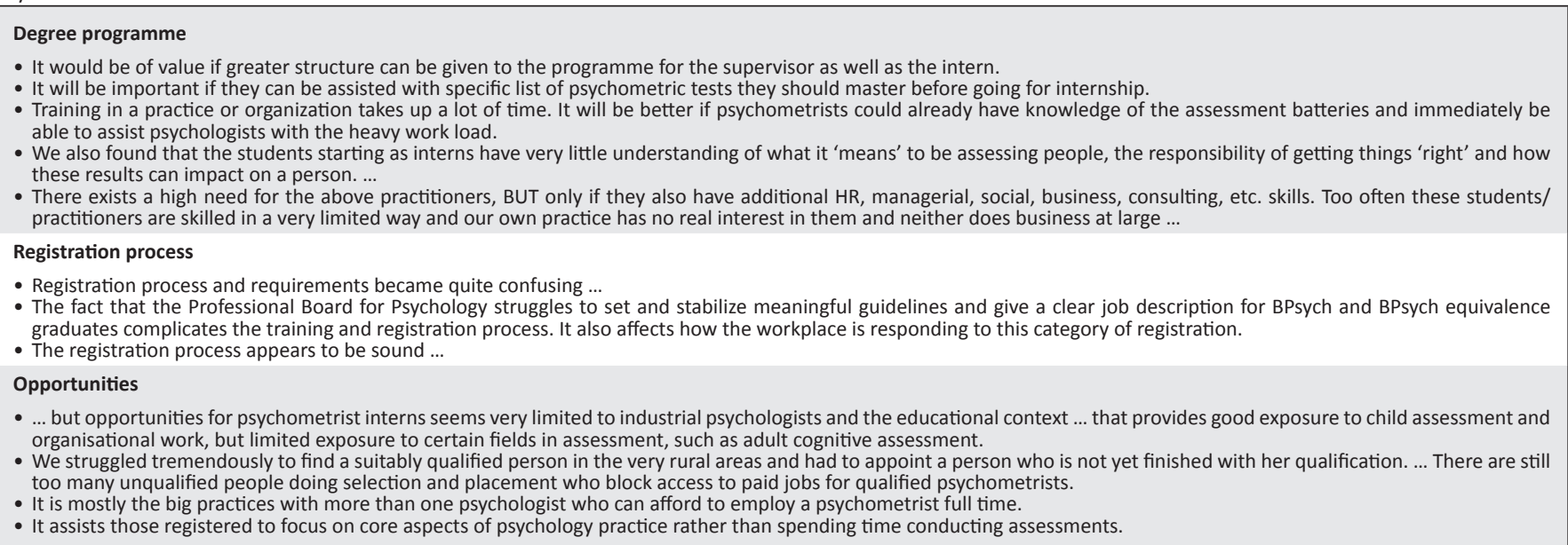

as psychometrist and six departments planning such a programme (refer to Table 4). With the exception of one current programme, these were all equivalence programmes.

The reasons provided for the termination of programmes were a lack of capacity to meet the training requirements (e.g. The HPCSA then required that we supervise ourselves, and given our lack of capacity ..., we discontinued the programme) and a perceived lack of job opportunities (e.g. ... the department feels there are not many job opportunities in this field and it will be in the students' best interest to rather register as counsellors; Our students weren't finding employment ...).

Details on the structure and content of training programmes (current or terminated) were obtained from seven departments. These programmes accommodated full-time students or a combination of full-time and part-time students with a median number of 40 students. On average 55\% of the students were white, 31\% black 4 , 9\% mixed-race and 5\% Indian. The theoretical component of the programmes varied, but in most cases more than one training strategy and form of 4.In two of the programmes, the majority of the students were black.
TABLE 4: Number of programmes terminated, current or planned per type of university department.

\begin{tabular}{lccc}
\hline Department & Terminated & Current & Planned \\
\hline Psychology & 5 & 1 & 5 \\
Industrial Psychology & 2 & 5 & 1 \\
Educational Psychology & - & - & - \\
\hline Total & $7 \dagger$ & 6 & 6 \\
\hline
\end{tabular}

$\dagger$, Four of these programmes were to be implemented again.

assessment were used. A variety of contexts were represented by the practical placements and these were selected either by the university or by the student. The primary supervisor was either a lecturer or a psychologist or psychometrist who was not based at the university. In some instances more than one supervisor was used with one being the lecturer. Reports on and supervision of the practicums were preferred by the departments as methods of assessment of the practicums.

\section{Discussion \\ Outline of the results}

The aim of the present study was to explore if the training of student psychometrists contributes to the relevance of this 
category in terms of the demographic profile of student psychometrists, the scope of services potentially provided by them and the content of training programmes.

\section{Demographic profile}

Although there were a few exceptions, the racial representation in the programmes as reported by seven of the university departments seems to reflect the published trend (e.g. Pillay et al. 2013; Pillay \& Siyothula, 2008). The lack of representation, in terms of the demographic profile of students and professionals in psychology in general, also applied to the student psychometrists who were registered in the Department of Psychology at UNISA. The majority of these students were female and more than half of the sample were white. The prevalence of female student psychometrists is not surprising given the national trend (Pillay \& Johnston, 2011). However, as emphasised by Pillay and Siyothula (2008), it is especially the racial skewness that impacts on the relevance of services provided in multicultural communities. According to these authors, an increase in numbers in the under-represented race groups alone will not guarantee relevant services.

\section{The scope of services}

One of the issues identified in the literature is the availability of professionals across different levels of registration. The availability of the psychometrist function is influenced by the training opportunities in this field and whether student psychometrists in fact register on completion of the training. Considering the findings based on the university survey, there seem to be limited training opportunities in this category, especially for students in the psychology and educational psychology departments. This was linked to limited job opportunities by some of the university departments. The consistency of teaching and training in industrial psychology departments (HPCSA, 2013) points to the utilisation of psychometrists as a professional resource in this field. However, this does not indicate the prevalence with which this function is undertaken by the psychometrist rather than the psychologist. Benjamin and Louw-Potgieter (2008) found that psychological assessment is to a large extent still included in the daily activities of the industrial psychologist. During the follow-up survey, one of the students stated that psychometrists pose a perceived threat to psychologists. In addition, the debate on the administration of certain tests by trained non-professionals is particularly relevant to industry and education (Foxcroft et al. 2013). This impacts on the opportunities for psychometrists. As a student remarked:

HR professionals are frequently utilising psychometric assessments or assessments with psychometric properties that are not registered as psychological by the HPCSA and can therefore be utilised by anyone undergoing the private training. These persons are often preferred as employees as they have HR knowledge ...

A relatively large percentage (62.3\%) of the cohort of student psychometrists in the present study were registered with the HPCSA, especially if one considers the low numbers reported for registered counsellors (Abel \& Louw, 2009; Elkonin \&
Sandison, 2006, 2010; Kotze \& Carolissen, 2005). However, given the time and effort that students invest in the programme, one would expect more of them to register. This issue was explored further by considering the students' and in-practice supervisors' reflections on the degree programme, registration and opportunities for student psychometrists and psychometrists that were obtained during the follow-up surveys. Similar to other studies, the reasons for not registering included problems with the registration process, pursuing an alternative registration category and perceived limitations in terms of job opportunities. Where the registration process was perceived as problematic, general administrative issues were mentioned together with specific references to the requirements made of foreign students. Despite the psychometrist function being regarded as a valuable resource, job opportunities were affected by costs, contexts and geographical area. Furthermore, respondents experienced situations where the work environment required context-specific skill sets, not usually included in the training of psychometrists.

A second problematic issue identified in the literature is the availability of services across geographical areas and sectors. A lack of equitable services is reflected in the concentration of placement opportunities and work contexts in certain geographical areas. Concerns raised by, amongst others, Pillay et al. (2013) on services being clustered in wealthier provinces and urban areas also applied to the present study. However, this distribution partly reflects the available opportunities. Approximately a quarter of the practical placements for the UNISA students were in the public sector and more than half in private practice with a relatively small number in the private sector. In the case of the work contexts, there was a somewhat more even distribution between private practice and the public sector. However, this trend does not necessarily reflect negatively on the availability of services. In addition to independent practitioners, there is a large group of smaller consultation firms operating in a private capacity but serving all sectors and a varied clientele.

In terms of the specific contexts, a small number of the UNISA students did their practical training in clinical contexts. The trainee's role, when assessing for emotional problems, rehabilitation, and so on, is limited in terms of the scope of practice for psychometrists. Changes in the HPCSA regulations (HPCSA, 2014b) resulted in the prohibition of placements in psychiatric settings and individual therapy. Despite the vast range of services in an educational context that relies on assessment, a relatively small number of student psychometrists in this sample were in placements affiliated to education departments, schools or other educational institutions. However, one should keep in mind that services provided in counselling contexts potentially overlap with those provided in the other contexts. Counselling and organisational contexts were best presented for the present cohort of student psychometrists.

\section{The content included in training programmes}

The training programme for psychometrists presented by the Department of Psychology at UNISA was based on the 
requirements of the Professional Board for Psychology of the HPCSA (2010, 2014b). According to these requirements, candidates have to successfully complete an accredited 4-year bachelor's degree in psychology (BPsych degree) or a qualification that has been accredited as equivalent to the BPsych degree. Furthermore, this qualification should be qualitatively different from an academic qualification (HPCSA, 2012); in that it should include teaching and assessment specifically focused on the integration of theory and practice. Meeting this requirement proved to be challenging in the case of the UNISA programme. The programme was therefore discontinued and is presently being restructured. In general, it seems as if the universities adhere to this requirement if one considers the variety of academic training and evaluation strategies reported at other universities. Elkonin and Sandison (2010) and Pillay and Johnston (2011), however, highlighted the difficulties in ensuring that this academic and professional teaching adequately prepare students for the practical placements.

The core skills areas included in the practical training of student psychometrists are: instrumental knowledge and skills; communication and interpersonal interaction; contingency management; and practice management and referral. Both students and in-practice supervisors who were involved in the UNISA programme indicated a need for greater preparation in terms of these skills areas during the academic teaching. For example, it was stated that training in the administration and interpretation of a broad range of tests should precede the placement. However, this has implications for the capacity required for the programme, an issue that is already perceived as problematic. In the case of the registered counsellor category, the HPCSA has specified a list of tests to be included in teaching and training (HPCSA, 2015a). This ensures some uniformity in the basic preparation across universities for this registration category. However, drawing up a generic list for student psychometrists might prove to be difficult given the variety of placement contexts and the fact that test use is to a large extent determined by the needs of a placement context. The list of tests commonly used by the cohort of student psychometrists in the present study could be a starting point when compiling such a list. An introduction to the remaining skills areas (as listed above) as part of the professional modules is feasible. A theoretical programme, however, cannot provide for all contexts, and experience in specific skills should be gained during the placement. This creates a dilemma that could impact on the use of psychometrists as a resource. As one in-practice supervisor commented: 'Too often these students/practitioners are skilled in a very limited way and our own practice has no real interest in them and neither does business at large ...'.

Candidates, in addition to the academic training, have to successfully complete an approved full-time practicum of 6-month duration, or an equivalent part-time practicum to be completed within a period of 12 months. The practical training has to be done in an appropriate context under the supervision of a registered psychologist or psychometrist (independent practice) (HPCSA, 2010, 2014b). The different universities placed their students in a variety of contexts to do the practical training. Although the HPCSA has clear expectations in terms of the selection of placements and the supervisory role of the university (HPCSA, 2012, 2014b), there seems to be, in practice, a degree of flexibility in the implementation of these aspects. The findings for the UNISA students indicate that the registration category of psychologists per se is not the issue but rather the experience of the in-practice supervisor. Although this expertise is invaluable in the success of the training, both the students and the in-practice supervisors expressed a need in the follow-up survey for more structure and greater involvement by the university during this phase of the training. In this regard, Elkonin and Sandison (2010) referred to the value of limiting the placements to pre-approved organisations and even to a specific geographical region. Potential partnerships between the university and placement organisations were mentioned by the students. Rotation of internships was also recommended to ensure variety in the training contexts.

The core of a test battery is selected according to the specific services provided by a placement and the age groups concerned. The UNISA students were expected to gain additional experience if such a battery was limited. In general, these students were exposed to the full range of tests as defined by the HPCSA (HPCSA, 2010, 2014b) during their training. Training should take cognisance of the broader societal context in which assessment is used (Laher \& Cockcroft, 2014). Furthermore, practices relating to computerised testing remain relevant and training in psychometrics per se is gaining importance (Labourwise, 2014; Pretorius, 2012). However, the follow-up surveys indicated that the use of computerised testing was less prevalent than what one would perhaps have expected. Most of the tests that were used by the cohort of student psychometrists in the present study were locally developed or adapted, and locally standardised. Although the use of local tests and local norms is a recommended practice, the possibility of dated norms exists. It should be kept in mind that, in a large number of placements, specific tests were also used and these were not necessarily standardised for the local context. Cockcroft, Turnbull and Van Ommen (2012) emphasised the need for research on the vast array of measures used locally, to determine their suitability in the multilingual and multicultural South African context. The theory and practice of multicultural assessment are generally emphasised during the academic teaching and the professional modules. The core skills areas included in the practical training of psychometrists also provide for sociocultural factors.

\section{Practical implications}

Capacity at the various universities impacts on the structure and content of the different programmes, and the equivalence option provides for variation in this regard. However, the Professional Board for Psychology of the HPCSA aims at greater alignment in training programmes at a national level (HPCSA, 2015b). Stakeholders have been invited to the 
related discussions and this is in line with the call by Ballim, Mabizela and Mubangizi (2014) for a framework that clarifies the role of the professional body and that of the universities in determining the theoretical and practical content of professional qualification programmes. The present study highlighted issues in terms of the structure of training programmes, training in professional skills and supervision that impact on the relevance of this professional category. This information, as summarised in the conclusion, could be applied in adapting existing programmes and in developing new programmes.

\section{Limitations and recommendations}

The findings for the student psychometrists who were registered at UNISA reiterated the issues raised in the literature for the profession of psychology in general. The open and distance learning nature of teaching at UNISA implies diversity in terms of demographics and geographical distribution thus contributing to the generalisability of these findings. However, diversity in the training models at the different training institutions imply that similar studies need to be done at other universities before a comprehensive picture of the national situation can be formed. Continued reflexive research is required for all professional categories, including the psychometrist category. Both training and practice should be considered. The latter implies the inclusion of a representative sample of psychometrists in future research.

\section{Conclusion}

The aim of the present study was to explore if the training of student psychometrists contributes to the relevance of this category. Specifically, issues concerning the demographic profile of student psychometrists, the scope of services potentially provided by them and the content of training programmes were investigated. Secondary data and survey research were used to explore if the training of student psychometrists contributes to the relevance of this category. A specific cohort of students was studied, and the findings were contextualised in terms of the national availability of training for psychometrists.

The skewness found in the demographic profile of the student psychometrists confirms the trends in professional psychology in general; in that the majority of the students were white females. Consideration of race and proficiency in indigenous languages in selection criteria will remain a priority. Pretorius (2012) recommended a mathematical and statistical background for student psychometrists to enable them to contribute to test development and assessmentrelated research. This recommendation should also be considered when defining selection criteria to ensure a person-environment fit (HPCSA, 2014b).

Considering the needs of the present student cohort and their in-practice supervisors, professional modules preceding the placement should include practical skills that could then be honed during the actual placement. This could prove to be challenging in programmes where the theoretical and practical training take place concurrently. The request for indepth preparation in a broad range of tests also has implications in terms of the capacity of those presenting the teaching. Another dilemma facing the developers and presenters of teaching and training programmes is the nonspecific nature of the registration category versus the contextspecific training implied by individual placements. Rotation in placements was suggested as a potential solution. The importance of the university's involvement during the practicum was emphasised.

The categorisation of psychometrist as a specialist skills area was seen as advantageous from a career perspective. The resource is used in all psychological service provision contexts (although the available training programmes seem to favour the organisational context). Concerns regarding the prevalence of services in private practice applied to the present student cohort, but it could be argued that independent practitioners and smaller consultation firms render counselling, educational and organisational services to all sectors. The expectations of potential placement organisations could limit opportunities for student psychometrists. However, finding a job after registration seemed to be a greater problem. Both the UNISA students and in-practice supervisors highlighted issues such as the cost related to the psychometrists' services, requirements for a skills set not necessarily included at second-tier registration and professional job reservation. Consideration of the findings of this study could enhance the existing value of the psychometrist category as a professional resource relevant to a variety of settings.

\section{Acknowledgements}

The authors thank Ms Liesl Strasheim for her support in capturing the secondary data.

\section{Competing interests}

The authors declare that they have no financial or personal relationships which may have inappropriately influenced them in writing this article.

\section{Authors' contributions}

R.v.E. (University of South Africa) was the project co-ordinator. R.v.E., V.v.D. (University of South Africa) and H.E. (University of South Africa) contributed to the survey development, data gathering and analysis, and the writing of the article.

\section{References}

Abel, E., \& Louw, J. (2009). Registered counsellors and professional work in South African psychology. South African Journal of Psychology, 39(1), 99-108. http:// dx.doi.org/10.1177/008124630903900109

Ballim, Y., Mabizela, S., \& Mubangizi, J.C. (2014). Professional bodies and quality assurance of higher education programmes in South Africa: Towards an appropriate framework. South African Journal of Higher Education, 28(4), 11401155.

Benjamin, J., \& Louw-Potgieter, J. (2008). Professional work and actual work: The case of industrial psychologists in South Africa. South African Journal of Psychology, 38(1), 116-135. http://dx.doi.org/10.1177/008124630803800107 
Cockcroft, K., Turnbull, O., \& Van Ommen, C. (2012). Editorial to the special issue: Cognitive science and neuropsychology. South African Journal of Psychology, 42(3), 368

Du Preez, E., \& Roos, V. (2008). The development of counsellor identity: A visual expression. South African Journal of Psychology, 38(4), 699-709. http://dx.doi. org $/ 10.1177 / 008124630803800409$

Elkonin, D.S., \& Sandison, A. (2006). Mind the gap: Have the registered counsellors fallen through? South African Journal of Psychology, 36(3), 598-612. http://dx. doi.org/10.1177/008124630603600310

Elkonin, D.S., \& Sandison, A. (2010). Perceptions of registered counsellor efficacy. South African Journal of Psychology, 40(1), 90-96. http://dx.doi. org $/ 10.1177 / 008124631004000109$

Foxcroft, C.D. (2011). Ethical issues related to psychological testing in Africa: What have learned (so far). Online Readings in Psychology and Culture, 2(2). http://dx. doi.org/10.9707/2307-0919.1022

Foxcroft, C., Roodt, G., \& Abrahams, F. (2013). Psychological assessment: A brief retrospective overview. In C. Foxcroft \& G. Roodt (Eds.), Introduction to psychological assessment in the South African context (4th edn.) (pp. 9-27). Cape Town: Oxford University Press.

Health Professions Council of South Africa (HPCSA). (2010). Training and examination guidelines for psychometrists (Form 94). Retrieved June 26, 2014, from http:// www.hpcsa.co.za/PBPsychology/Guidelines.

Health Professions Council of South Africa (HPCSA). (2012). The Unisa BPsych Equivalence Programme. Evaluation report presented to the Department of Psychology. Pretoria: HPCSA.

Health Professions Council of South Africa (HPCSA). (2013). B.Psych information for registered counsellors and psychometrists. Report. Pretoria: HPCSA.

Health Professions Council of South Africa (HPCSA). (2014a). iRegister. Retrieved June 26, 2014, from http://isystems.hpcsa.co.za/iregister

Health Professions Council of South Africa (HPCSA). (2014b). Training and examination guidelines for psychometrists (Form 94). Retrieved November 05, 2014, from http://www.hpcsa.co.za/PBPsychology/Guidelines

Health Professions Council of South Africa (HPCSA). (2015a). Framework for education training, registration and scope of registered counsellors (Form 258). Retrieved July 31, 2015, from http://www.hpcsa.co.za/PBPsychology/Guidelines

Health Professions Council of South Africa (HPCSA). (2015b). Agenda for the BPsych and BPsych Equivalent Stakeholder meeting arranged by the Professional Board for Psychology for 28 May 2015 at Birchwood, Johannesburg.

Hill, C., Nel, J.A., Van de Vijver, F.J.R., Meiring, D., Valchev, V.H., Adams, B.G. et al. (2013). Developing and testing items for the South African Personality Inventory (SAPI). South African Journal of Industrial Psychology, 39(1), Art. \#1122, 13 pages. http://dx.doi.org/10.4102/sajip.v39i1.1122

Jordaan, I., Spangenberg, J.J., Watson, M.B., \& Fouché, P. (2007). Emotional stress and coping strategies in South African clinical and counselling psychologists. South African Journal of Psychology, 37(4), 835-855. http://dx.doi.org/10.1177/ 008124630703700411

Kotze, L., \& Carolissen, R. (2005). The employment patterns of BPsych students in the Western Cape. Paper presented at the 11th South African Psychology Congress, Cape Town.

Labourwise. (2014). Employment Equity Act amendments effective from 1 Augus 2014. Retrieved November 12, 2014, from http://www.labourwise.co.za/labourarticles/ee-amendments
Laher, S., \& Cockcroft, K. (2013). Psychological assessment in South Africa: Research and applications. Johannesburg, South Africa: Wits University Press.

Laher, S., \& Cockcroft, K. (2014). Psychological assessment in post-apartheid South Africa: The way forward. South African Journal of Psychology, 44(3), 292-302. http://dx.doi.org/10.1177/0081246314533634

Metzer, S.A., De Bruin, G.P., \& Adams, B.G. (2014). Examining the construct validity of the Basic Traits Inventory and the Ten-Item Personality Inventory in the South African context. South African Journal of Industrial Psychology, 40(1), Art. \#1005, 9 pages. http://dx.doi.org/10.4102/sajip.v40i1.1005

Mulder, G., Jorgenson, L.I., Nel, J.A., \& Meiring, D. (2013). The evaluation of a frameof-reference training programme for intern psychometrists. South African Journal of Human Resource Management, 11(1), Art. \#506, 10 pages. http://dx.doi. org/10.4102/sajhrm.v11i1.506

National Association of Psychometrists (NAP). (2014). What is a psychometrist? Retrieved September 29, 2014, from http://www.napnet.org

Nell, V. (1999). Standardising the WAIS-III and the WMS-III for South Africa: Legislative psychometric and policy issues. South African Journal of Psychology, 29, 128-138. http://dx.doi.org/10.1177/008124639902900305

Pillay, A.L., Ahmed, R., \& Bawa, U. (2013). Clinical psychology training in South Africa: A call to action. South African Journal of Psychology, 43(1), 46-58. http://dx.doi. org/10.1177/0081246312474411

Pillay, A.L., \& Harvey, B.M. (2006). The experiences of the first South African community service clinical psychologists. South African Journal of Psychology, 36(2), 259-280. http://dx.doi.org/10.1177/008124630603600204

Pillay, A.L., \& Johnston, E.R. (2011). Intern clinical psychologists' experiences of their training and internship placements. South African Journal of Psychology, 41(1) 74-82. http://dx.doi.org/10.1177/008124631104100108

Pillay, A.L., \& Kritzinger, A.M. (2007). The dissertation as a component in the training of clinical psychologists. South African Journal of Psychology, 37(3), 638-655. http://dx.doi.org/10.1177/008124630703700315

Pillay, A.L., \& Siyothula, E.B. (2008). The training institutions of black African clinical psychologists registered with the HPCSA in 2006. South African Journal of Psychology, 38(4), 725-735. http://dx.doi.org/10.1177/008124630803800411

Pretorius, G. (2012). Reflections on the scope of practice in the South African profession of psychology: A moral plea for relevance and a future vision. South African Journal of Psychology, 42(4), 509-521.

Schaap, P. (2011). The differential item functioning and structural equivalence of a nonverbal cognitive ability test for five language groups. South African Journal of Industrial Psychology, 37(1) Art. \#881, 16 pages. http://dx.doi.org/10.4102/sajip. Industrial

Schoeman, A., De Beer, M., \& Visser, D. (2008). The relationship between learning potential, English language proficiency and work-related training test results. South African Journal of Labour Relations, 32(1), 47-62.

Van Eeden, R., Van Deventer, V., \& Erasmus, H. (July 2015). Training opportunities for registration as a registered counsellor or psychometrist in South Africa. Paper presented at the 17th Annual SIOPSA Conference, Pretoria.

Van Zyl, C.J.J., \& Taylor, N. (2012). Evaluating the MBTI ${ }^{\circledR}$ Form M in a South African context. South African Journal of Industrial Psychology, 38(1), Art. \#977, 15 pages. http://dx.doi.org/10.4102/sajip.v38i1.977

Visser, D., \& Viviers, R. (2010). Construct equivalence of the OPQ32n for Black and White people in South Africa. South African Journal of Industrial Psychology, 36(1), Art. \#748, 11 pages. http://dx.doi.org/10.4102/sajip.v36i1.748 